\title{
Chaves para ler as Memórias inventadas, de Manoel de Barros
}

Raquel R. Souza ${ }^{1}$

Já faz algum tempo, propus uma arquitetura essencial, que a meu ver está contida em toda a palavra autobiográfica, mesmo aquela que se mostra avessa às "etiquetas" ou às classificações teoréticas como "autobiografia" (Souza, 2002). Na ocasião, trabalhava com a poesia de Drummond, especialmente a série Boitempo, constituída de três volumes nos quais o poeta mineiro "narra" sua própria vida. Defendi a ideia de que a organização da palavra autobiográfica é feita na construção de um triângulo cujas paredes são formadas pelo Tempo, pela História e pela Memória. Os lados desse triângulo não estão em subserviência entre si; estão, sim, imbricados uns com os outros, mas, por necessidade de sistematização, trabalhei em separado cada uma dessas categorias. Refiro esse trabalho porque é a partir dessa arquitetura triangular que retomo meu olhar sobre a memória. No entanto, preciso isolá-la relativamente dos outros componentes da figura.

Por outro lado, como estou pinçando o tema da memória a partir de uma visada teórica sobre as escritas autobiográficas - e hoje já é consenso vislumbrá-las como construções ficcionais de si mesmo -, de minha parte, independente de o autor buscar um jogo de ficcionalidades para aquilo que narra como autobiografia e congêneres, julgo que essas estratégias narrativas nada mais são do que jogos divertidamente sérios. Reafirmo que o alicerce para esse tipo de narrativa (o gênero autobiográfico) é o mesmo: a história, o tempo, a memória. O jogo, a brincadeira, as dissimulações, os pactos de leitura são as possibilidades de estratégias narrativas que são reinventadas caso a caso. À primeira vista, são esses jogos que chamam a atenção do leitor e do crítico para a construção autobiográfica de Manoel de Barros, de cuja obra elejo Memórias inventadas: a infância ${ }^{2}$, que, ao lado de mais dois volumes, compõe sua autobiografia.

\footnotetext{
1 Doutora em letras. Professora associada de literatura brasileira no Instituto de Letras e Artes e no Programa de Pós-Graduação em Letras da Universidade Federal do Rio Grande (FURG), Rio Grande, Brasil. E-mail: raquelrolandos@hotmail.com.

${ }^{2}$ Estou usando precisamente a primeira edição de 2003. No entanto, como a apresentação em forma de livro foi alterada pelo poeta, não há numeração das páginas; apenas os números romanos enumerando os episódios rememorados. Dessa maneira, forçosamente usarei como indicação das citações os respectivos títulos que encabeçam os episódios.
} 
Mas, para melhor expor, quero ressaltar que a profusão de tipologias para as mais diversas linhagens da palavra autobiográfica tem sido a tônica nos últimos anos, tanto aqui no Brasil quanto em outros países na América e da Europa. O interessante é que esse fenômeno teórico-críticoeditorial se estende igualmente a outras áreas do conhecimento. Mas essa seria uma discussão muito longa e que, no momento, não faz parte de minhas preocupações. Explico-me um pouco melhor: não pretendo dar ênfase às tipologias, tais como as angústias classificatórias de "autobiografia versus autoficção" ou, ainda, os traços distintivos entre as mais diversas formas autobiográficas para as escritas do eu.

Basta-me a perspectiva de estar trabalhando com um texto reconhecidamente afeito à palavra autobiográfica, e como tal o leio. Meu desejo é tão somente usufruir da narrativa lírica do poeta goiano e de suas memórias advertidamente inventadas. Como tenho trabalhado com algumas perspectivas da Filosofia do Imaginário e, sobretudo, com a fenomenologia de Bachelard, pergunto-me: afinal, o que busco? A possível resposta é: recompor na memória de Manoel as minhas memórias inventadas da infância. Isso será possível porque o próprio poeta indica o caminho, pois chama suas memórias de memórias "inventadas". E, se são "inventadas", o leitor também poderá inventá-las. Eu também.

Ademais, como esboçarei adiante, me interesso por uma imagem que me acorre, a de uma chave que se encontra timidamente escondida nos capítulos dessas memórias. Uma chave que possa abrir outra possibilidade de leitura. Tento explicar: o subtítulo - a infância - traz um apelo muito forte, que circunscreve a memória a um tempo quase idílico do poeta, e que é referendado por sua poética, notadamente alicerçada em uma linguagem "primitiva" que faz referência à infância. Isso, de certo modo, direciona previamente a leitura dessas memórias. Na contramão, busco outra perspectiva, aquela que abra para confissões íntimas do poeta e de sua poesia, na qual a infância é apenas a referência temporal, e não seu centro irradiador. Essa imagem, a da chave, como é de se esperar desse elemento simbólico, tanto abre quanto fecha, e também provoca questões relativas ao pacto de leitura, tema muito afeito a essas memórias como também a todo trabalho investigativo sobre as produções autobiográficas. Entretanto, penso não em um contexto de pacto de leitura propriamente dito, mas sim em uma de suas múltiplas leituras para o verdadeiramente inventado conteúdo dessas memórias.

Como uma narrativa de nascimento, trata-se das memórias da poesia, e não propriamente do homem, pois é na confluência (ou será confusão?) deste com aquela que se dão as pequenas narrativas que compõem 
o volume. A infância aparece como espaço da memória onde se fizeram os primeiros registros do sentimento da palavra poética.

\section{A memória que se imagina}

É preciso escolher. Quero dizer, a categoria da memória abre seu leque e as inúmeras alternativas exegéticas saltam com tamanha força que podem baquear minha intenção de pensar a memória no livro de memórias de Manoel de Barros, o qual, a rigor, se sabe ter escrito (e ainda escreve) uma poesia mergulhada no memorialismo. As classificações são variadas. Há as preocupações teóricas da memória coletiva em suas diversas acepções, assim como os estudos relativos à memória individual em variados matizes; há igualmente trabalhos de intensa busca arqueológica para a compreensão dos processos mnemônicos; e há também aqueles em que fulguram os aportes das ciências biomédicas. De minha parte, em artigo recente (2010), optei por enfrentar os desafios da memória entendendo-a na sua intrínseca relação com o movimento.

Memória é movimento, afirmei anteriormente, mas um movimento que transcende as localizações físicas do espaço e do tempo. E, por ser movimento, é também imaginação. A memória vive das imagens que transitam do canto escuro do passado para as iluminações do presente. Diz o poeta-autobiógrafo: "Eu ia dizer sem pudor que o escuro me ilumina. É um paradoxo que ajuda a poesia e que eu falo sem pudor" "Manoel por Manoel"). A iluminação do presente é argumento para a "teoria dos achadouros". Folheando as partes do livro-caixinha de Manoel, cuja composição gráfica mencionarei mais adiante, deparo-me com "Achadouros", e o poeta diz:

Mas eu estava a pensar em achadouros de infâncias. Se a gente cavar um buraco ao pé da goiabeira do quintal, lá estará um guri ensaiando subir na goiabeira. Se a gente cavar um buraco ao pé do galinheiro, lá estará um guri tentando agarrar no rabo de uma lagartixa. Sou hoje um caçador de achadouros de infância. Vou meio dementado e enxada às costas a cavar no meu quintal vestígios dos meninos que fomos ("Achadouros").

Há, por certo, uma "teoria dos achadouros", que é atravessada pela cosmovisão do elemento terrunho. Os valores simbólicos contidos nesse fragmento são muitos, mas fico, por enquanto, com o verbo "cavar", que aparece duas vezes atrelado ao "buraco": cavar um buraco no pé da goiabeira e cavar um buraco no pé do galinheiro, de onde brota a criança 
(guri) em peraltagens. É a essa memória que me refiro. A escavação do buraco na terra, indiciando um poço, é uma linda metáfora para a memória; do escuro no fundo do poço, o adulto resgata o menino (o guri) e o traz à luz. Da memória, isto é, do poço, como uma gruta verticalizada no centro da Terra, brotam as imagens animadas pelos valores emocionais que as despertaram ${ }^{3}$. Bachelard (1988) dizia que a infância é o poço do ser. O adulto, que escreve suas memórias "inventadas", tornou-se o caçador de achadouros de infância ${ }^{4}$.

Por outro lado, o poeta também abre uma interessante perspectiva acerca da memória. Ao aliá-la à terra, notadamente visível nas significações do verbo "cavar" e dos substantivos "goiabeira", "galinheiro" e "enxada", define que os resultados de suas escavações serão "vestígios dos meninos que fomos" ("Achadouros"). Ora, tal acepção remete à forma fragmentada e imprecisa da memória, porque ela não acorre de forma inteiriça, mas sim por vestígios, isto é, rastro, pegada, pista, como também estigma, sombra, restos. $\mathrm{O}$ "vestígio", palavra altamente significativa para o contexto de qualquer obra do gênero autobiográfico, desvela, por meio do episódio "Achadouros", o procedimento estético-emocional com o qual Manoel compôs Memórias inventadas.

Corroborando essa mesma linha de proposta para pensar a Memória, que na de Manoel tem o adjetivo "inventada" a lhe caracterizar, quero trazer uma linda metáfora que me dá sustentação teórica de outro ponto de vista, para ver a ficção como íntima aliada na confecção das memórias. Refiro-me à imagem de afresco, como ocorreu a Stendhal; a citação é um pouco longa, mas elucidativa:

Ao escrever minha vida, em 1835, fiz muitas descobertas, de dois tipos: antes de mais nada, primeiro estão os grandes pedaços de afrescos sobre uma parede, que costumam permanecer muito tempo esquecidos, e de repente reaparecem, e com estes pedaços bem conservados existem, como já disse várias vezes, grandes espaços onde não se vêem mais do que os tijolos da parede. O revestimento, o reboco sobre o qual o afresco havia sido pintado, se despreende

\footnotetext{
3 A gruta pode, em muitos casos, assumir esta imagem verticalizada; para maiores observações, ver Bachelard (2003).

4 Curiosamente reparo que o fragmento acima, pelo verbo cavar, remete ao capítulo "Escova”, o primeiro na sequência dos treze de que são compostas essas memórias da infância, porque, como mencionarei adiante, o ato de cavar é aliado ao de escovar osso dos arqueólogos aos quais o poeta queria se aparentar, com “escovar palavras”, numa alusão à metapoesia.
} 
e cai, e o afresco se perde para sempre. Nos pedaços conservados não há datas (Stendhal apud Miraux, 2005, p. 69, tradução minha).

Na sequência da narração de Stendhal se percebe sua intenção de justamente explicar e argumentar a favor da ficcionalidade inerente à obra autobiográfica. Para o escritor francês, ainda que um autor se predisponha a contar sua própria vida, forçando, assim, uma ideia de total fidedignidade ao passado, isso não é possível. Stendhal diz que não pode entregar ao leitor a realidade dos feitos, dos acontecimentos, mas sim oferecer a sombra $^{6}$ desses fatos, desses acontecimentos. Ora, a escritura autobiográfica é a presença de simulacros.

Miraux (2005), pensando a memória nas autobiografias, sintetiza muito bem: diz que o esquecimento impede a pessoa de contar a história de sua vida, mas trata-se de um esquecimento fecundo, porque seleciona o essencial e apaga o episódico. E mais: é na escritura o lugar onde se produz a recordação significativa da vida; o esquecimento suscita a imaginação; expõe de maneira aguda a relação entre o referencial e o poético. "Não é a exatidão dos fatos o que importa, mas o encontro do fato relatado e do imaginário, que o reproduz" (Miraux, 2005, p. 70, tradução nossa) ${ }^{7}$. Claro está que essas palavras nos conduzem à evidente ficcionalização inerente à palavra autobiográfica.

E volto a afirmar: não à toa, Manoel explicita a relação da memória com a ficcionalidade, porque intitula seu texto de "memórias inventadas"; e mais, a epígrafe de suas memórias diz: "Tudo o que não invento é falso". Ele inverte, pelo uso da negativa como premissa básica, o que se chama de "verdade", porque o "falso" é o antônimo do "verdadeiro". Nesse jogo de negativas, o poeta reafirma seu credo na imaginação.

Eu tenho um ermo enorme dentro do olho. Por motivo do ermo não fui um menino peralta. Agora tenho saudade do que não fui. Acho

\footnotetext{
5 "Al escribir mi vida en 1835, hice muchos descubrimientos, de dos espécies: ante todo, primero estan los grandes trozos de frescos sobre uma pared, los que tras permanecer largamente olvidados, de pronto reaparecen y junto a estos trozos bien conservados hay, como lo he dicho varias veces, grandes espacios donde no se ven más que los ladrillos de la pared. El revestimiento, el revoque sobre el que había sido pintado el fresco se desprende y cae, y el fresco se pierde para siempre. En los trozos conservados no hay fecha."

${ }^{6}$ Ressalto que o termo, além de perigoso, admite perspectivas teóricas distintas. Não pretendo, no momento, avançar nesse problema teórico sobre os termos "sombras", "simulacros", "devaneios", e outros afins. Demarco, isso sim, que "sombra" está em referência à "imagem" do objeto, e não ao próprio, daí a ideia de "simulacro" para as autobiografias, ideia esta que não carrega o sentido negativo do termo.

7 "No es la exactitud de los hechos lo que importa, sino el encuentro del hecho relatado y del imaginario, que lo reproduce."
} 
que o que faço agora é o que não pude fazer na infância. Faço outro tipo de peraltagem ("Manoel por Manoel").

Esse tipo de revelação está disseminado em todo o volume de suas Memórias inventadas. Isto é, a relação entre aquilo que não é com aquilo que ele deseja que seja: "Em vez de peraltagem eu fazia solidão. Brincava de fingir que pedra era lagarto. Que lata era navio. Que sabugo era um serzinho mal resolvido e igual a um filhote de gafanhoto" ("Manoel por Manoel"). O poeta guarda no adulto a mesma vontade de brincar da criança que já foi.

\section{O tempo e o não tempo}

Gostaria de observar que os episódios que compõem essa autobiografia, ou "memórias inventadas", não têm data e tampouco vêm organizados por uma linha sequencial de tempo. São, isso sim, dispostos na confecção de uma narrativa autobiográfica sob outro regime, o dos valores afetivo-emocionais das descobertas do menino e do adulto, e das coisas que vivem a poesia. E mais uma vez retorno a Bachelard: "A história de nossa infância não é psiquicamente datada. As datas são respostas a posteriori; vêm dos outros, de outro lugar, de um tempo diverso daquele que se viveu" (Bachelard, 1988, p. 100). Essas "memórias inventadas" se realizam no devaneio, que não tem datas.

Ele, o devaneio, é o caminho profícuo para a realização literária, tal como foi explicitado por Bachelard. Penso, particularmente, nos conceitos "sonho desperto" e "devaneio"8. Neles, a memória é essencial. Agripina Ferreira, que dicionarizou termos do filósofo francês, assim define o devaneio:

O produto do cogito de um sonhador e tem como ponto de partida alguma coisa do presente ou do passado (...). As barreiras impostas pelo tempo linear são superadas. As reminiscências de um longínquo passado retornam ao presente, alojando-se, abrigando-se na alma do sonhador (Ferreira, 2008, p. 57).

Interessante na autobiografia do poeta goiano é reparar que as marcações verbo-temporais vêm declinadas no pretérito, o que de certa maneira assevera o postulado aristotélico de que "a memória é do passado", como

\footnotetext{
${ }^{8}$ É preciso opor o sonho desperto ao sonho noturno: “O sonhador do sonho noturno é uma sombra que perdeu seu eu, o sonhador de devaneio, se for um pouco filósofo, pode, no centro do seu eu sonhador, formular um cogito. Dito de outro modo, o devaneio é uma atividade onírica na qual subsiste uma clareza de consciência. O sonhador de devaneio está presente em seu devaneio” (Bachelard, 1988, p.13).
} 
insistiu Ricoeur (2007, p. 35). Mas o narrador que declina no passado assume também uma postura do ser devaneante que se mantém como animus, porque deixa bem definidas as identidades do eu-do-passado e do eu-atual. Agripina Ferreira (2008) assim define o verbete "animus e anima" em seu dicionário:

Nas profundezas do psiquismo de todo ser humano existe um animus e uma anima. Esta dualidade está sempre presente e atuante. Nos instantes de solidão, quando o sonhador em seus devaneios ultrapassa o mundo da percepção, indo para um espaço imaginário, sua anima liberta, e em expansão lhe proporciona esse encantamento, fazendo-a sonhar. Ao animus pertencem todas as atividades do 'pensamento claro', da razão (Ferreira, 2008, p. 23).

No que concerne ao devaneio propriamente dito, retorno ao filósofo francês, que dizia:

O devaneio é uma mnemotécnica da imaginação. No devaneio retomamos contato com possibilidades que o destino não soube utilizar. Um grande paradoxo está associado aos nossos devaneios voltados para a infância: esse passado morto tem em nós um futuro, o futuro de suas imagens vivas (Bachelard, 1988, p. 107).

A ação aconteceu no pretérito, como indica o verbo, mas seus efeitos se estendem ao presente e, por isso, contrariando a lógica aristotélica que Ricoeur recupera, atrevo-me a dizer que a memória pertence ao presente, porque aquilo que a memória de alguma forma recupera do passado é reconduzido ao presente daquele que relembra. E assim se revive outra vez e mais outra e mais outra.

Em "Cabeludinho", o narrador se localiza em umas férias de regresso à casa dos avós; comenta sobre a maneira de sua avó falar deslocando as preposições e relembra uma pelada com a criançada, quando um menino lhe grita:

- Disilimina esse, Cabeludinho. Eu não disiliminei ninguém. Mas aquele verbo novo trouxe um perfume de poesia à nossa quadra. Aprendi nessas férias a brincar de palavras mais do que trabalhar com elas. Comecei a não gostar de palavra engavetada ("Cabeludinho"). 
E mais: "Por depois ouvi um vaqueiro a cantar com saudade: Ai morena, não me escreve / que eu não sei a ler. Aquele a preposto ao verbo ler, ao meu ouvir, ampliava a solidão do vaqueiro" ("Cabeludinho").

A presentificação desse passado, que a memória inventivamente selecionou, vem no apelo do movimento do tempo pela conjugação do verbo no imperfeito do indicativo - "ampliava a solidão do vaqueiro", pois é a mesma solidão do devaneador da infância. Com raras exceções, os episódios que a memória do poeta renomado reimaginou são marcados pelo mesmo tempo verbal. Isso se dá na medida em que a proposta é mesmo o relato de determinadas redescobertas do adulto, face ao que ressignificou quando era o menino. A memória, na sua autobiografia, almeja recompor a história que "explica" a poesia do velho Manoel de Barros, agora, no tempo da escrita, com oitenta e cinco anos.

\section{A chave pendurada no poeta}

No tempo das memórias, usualmente se recorda a infância. A explicação é de Bachelard (1988, p. 102): "É no último quartel da vida que compreendemos as solidões do primeiro quartel, quando a solidão da idade provecta repercute sobre as solidões esquecidas da infância". Manoel, agora, brinca com as palavras, de escovar palavras. No capítulo "Escova", diz:

É que eles queriam encontrar nos ossos vestígios de antigas civilizações que estariam enterrados por séculos naquele chão. Logo pensei em escovar palavras. Porque eu havia lido em algum lugar que as palavras eram conchas de clamores antigos. (...) eu já sabia também que as palavras possuem no corpo muitas oralidades remontadas e muitas significâncias remontadas ("Escova").

Manoel está se referindo a um episódio de sua vida em que o menino deseja realizar o mesmo trabalho dos arqueólogos: escovar osso. Trata-se, na verdade, do primeiro capítulo de suas memórias inventadas. Entretanto, é um capítulo que inaugura o tema da memória no qual a seleção de imagens e sentimentos tem por critérios os valores da poesia do chão, das formigas, da infância livre e sem comparamentos, e não os fatos que factualmente podem ter acontecido.

O livro busca a memória do poeta ao fazer poesia, reimaginando aqueles momentos inaugurais dos sentimentos e das percepções sobre os seus temas poéticos vigentes ainda hoje. Ele alia a memória à metapoesia, de maneira que suas memórias são as que o poeta inventa (porque 
"inventadas") no surgimento da poesia em sua vida. O que aparece por trás dos afrescos, como dizia Stendhal, não é a história do homem, mas sim a história da poesia que se instala no poeta; é ela, a própria poesia, quem tem lugar de prevalência nas memórias de Manoel de Barros. Tratase, enfim, da memória da poesia: "Então eu trago das minhas raízes crianceiras a visão comungante e oblíqua das coisas", diz o poeta no capítulo que informa "Manoel por Manoel".

Já em outro, intitulado "Fraseador", o poeta esclarece objetivamente, demarcando as datas: "Hoje eu completei oitenta e cinco anos. O poeta nasceu de treze" ("Fraseador"). Anoto que esse é o único que vem com uma data marcada, melhor dizendo, com uma referência de idade, e que não é propriamente uma data. Está mais para marcar os longos anos de vivência da poesia. Por outro viés, a referência aos seus treze anos como ponto inicial do poeta se repete na estruturação do livro. Certamente não é aleatório o número de capítulos - treze. Difícil precisar uma simbologia numérica unificada para o número treze.

No entanto, ainda que na Antiguidade o número tenha sido relacionado ao mau agouro, entre as diversas culturas, o "treze" traz consigo, de uma forma geral, uma correspondência ao recomeço após a conclusão de um ciclo a partir da relação com a Morte, o décimo terceiro arcano superior do Tarô: doze mais um $(12+1=13)$; é a memória imaginada que localiza o fim de um ciclo - o menino sem poesia - e o recomeço de um outro ciclo - o menino que, impregnado de poesia, inicia suas atividades de poeta. Pois é aos treze que Manoel diz ter nascido o poeta.

Mas há também a ideia de um refazer que, como Sísifo, repete ininterruptamente ao longo dos anos o mesmo trabalho incansável - no caso do poeta, os temas e os seu modo peculiar de trabalhar com a palavra poética, quebrando-a e remontando-a em outras significações, isto é, o valor primitivo delas, ou como ele mesmo chama: "escovar palavras". Há que lembrar, por fim, que "na última refeição de Cristo com os seus Apóstolos, na Ceia, eram treze os presentes. A Cabala enumerava treze espíritos do mal. O décimo terceiro capítulo do Apocalipse é o do Anticristo e da Besta (Chevalier e Gheerbrant, 1997, p. 902). Essa figuração do treze como o mal remete a valores simbólicos que parecem estar conjugados no todo da sua obra, mas que nas suas "memórias inventadas" aparecem de uma maneira mais visível como memória da poesia brasileira.

Em outro momento, intitulado "Desobjeto", Manoel recupera uma imagem poética muito forte na poesia brasileira - a do poeta Carlos, o gauche na vida do "Poema de sete faces", de Drummond. E assume, dessa maneira, uma memória poética que há muito transita pelo tema do 
baixo, mas que no Brasil foi mantida às escondidas, a principiar pelo Boca do Inferno, passando pelos poetas românticos e a poesia pornográfica de Bernardo Guimarães, chegando, evidentemente, a Augusto dos Anjos.

Com o Modernismo, caso de Drummond, de Bandeira e de tantos outros, o tema do baixo em todos os seus matizes foi perdendo a aura de maldição e ganhou foros de afeição aos "desobjetos", como lhes chama o Manoel de Barros: "O menino que era esquerdo e tinha cacoete pra poeta, justamente ele enxergara o pente naquele estado terminal" (Desobjeto). Não faltam, nessa composição, alguns elementos simbólicos muito presentes em sua poesia, desde Poemas concebidos sem pecados (1937) até Menino do mato (2010). O caramujo, o sapo, as camadas de areia, as formigas, o musgo, o osso, o lagarto 9 são todos substantivos que comandam as imagens poéticas da memória de Manoel, ou como ele adverte na "Entrada" à sua Poesia completa: "Então comecei a fazer desenhos verbais de imagens" (2010, p. 7).

Corroborando, saliento que é sintomático o capítulo "Obrar", que recupera pela memória afetiva do aprendizado os valores que irão ajudar o poeta, no futuro, a compor sua obra poética. Em suas Memórias inventadas, a modo de metapoesia, Manoel elege o episódio singular ocorrido numa tarde de outono, ao pé da roseira de sua avó. O fato sobre o qual a memória "inventa" todo o resto foi o ato de defecar no pé da roseira. O eu-lírico (nesse episódio o autor adotou o formato poemático) explicita as significações do verbo "obrar", que dá título ao capítulo, adotando seu sentido popular e rural. Naturalmente o tema não parece muito sugestivo para compor um poema, mas ele o faz para reafirmar suas escolhas temáticas, as quais são marcadas pela aparente singeleza das imagens como também por um intrínseco entrelaçamento do alto (o tema da roseira) com o do baixo (defecar em seu pé). Diz o poeta:

Eu só obrei no pé da roseira da minha avó

(...)

Daí que também a avó me ensinou a não desprezar as coisas

Desprezíveis

E nem os seres desprezíveis

("Obrar").

\footnotetext{
${ }^{9}$ Lembro, neste momento, que Drummond, em sua autobiografia, a série Boitempo, dedica um poema a sua insistente prática no quintal da casa paterna em catar cacos de vidros enterrados pelo tempo e pelos moradores do sobrado mineiro. Solitário na brincadeira, também era visto como um "esquerdo" entre os seus familiares. Ver Souza (2002).
} 
As rememorações do poeta adulto reiluminam o menino quando este descobre a literatura, e sugerem explicações para seu fazer poético. O capítulo "Parrrede!", na sequência de "Desobjeto", igualmente reverbera a memória da poesia. Adotando uma forma poemática mais visível, porque feita de versos, ainda que livres, o eu-lírico declinado no pretérito localiza temporalmente através da memória, pela conjunção temporal "quando" o espaço do acontecimento -, o colégio interno. Sob pretexto da descoberta do prazer solitário da masturbação, o menino-Manoel foi penalizado com a leitura, também solitária, dos Sermões de Padre Vieira: "Aprendi a gostar do equilíbrio sonoro das frases. / Gostar quase até do cheiro das letras" ("Parrrede!"). A leitura dos Sermões carrega a memória do prazer.

\section{A chave e a caixinha do Manoel}

Na tangência da memória com o tempo e com a história, arquitetura fundamental para a palavra autobiográfica, pergunto-me mais uma vez: e a memória, como é a memória daquele que se joga à palavra admitida como autobiográfica? Como a memória atua nas mentes dos poetas que têm, por natureza do lírico, certa dificuldade em inserir-se no decurso de tempo e que, em geral também não se preocupam com a historicidade? Pinçando algumas palavras de Todorov (2000), relembro que a memória não se opõe ao esquecimento; antes, os termos mais ajustados para se contraporem são a "supressão" e a "conservação", da mesma maneira como exemplifica a metáfora de Stendhal antes mencionada. É na interação desses dois movimentos que a memória é produzida, porque o restabelecimento integral do passado é uma impossibilidade. Aliás, Jean Pouillon (1974) já fez essa observação há alguns anos, quando esclareceu que aquilo que a memória estrita traz é a mentira.

Contudo, Todorov reitera algo que há muito já se sabe, isto é, que a memória é uma seleção, e só se conserva aquilo que se elege. E mais ainda: como a memória é um ato seletivo, essa seleção é feita a partir de determinados critérios, os quais, conscientes ou não, servirão igualmente para a utilização que faremos do passado (Todorov, 2000, p. 16). E, por fim, de Todorov interessa-me ressaltar que "a memória não é responsável apenas por nossas convicções, mas também por nossos sentimentos" (Todorov, 2000, p. 26, tradução nossa) $)^{10}$.

\footnotetext{
10 "La memoria no es sólo responsable de nuestras convicciones sino también de nuestros sentimientos."
} 
Raquel R. Souza

Certo é que o poeta goiano, ao conservar determinados episódios em detrimento de outros, conscientemente selecionou aquilo que lhe servirá como explicativo de sua poética. Esses são seus critérios para a sua memória, critérios que são reiterados sob o tema da metapoesia. Curioso notar que ele segue na contramão do usual das autobiografias contemporâneas, porque não esboça dúvidas quanto àquilo que pretende narrar como seu próprio aprendizado, muito menos a angustiosa perquirição do eu. O narrador não se questiona, não titubeia, não condiciona sua palavra autobiográfica a nada. Ele não está preocupado em reviver o passado para encontrar explicações para seu presente. É opinião de Miraux que a escritura autobiográfica moderna é intersticial, elíptica, e que esses elementos "convertem-se na própria condição da escrita autobiográfica, que desenvolve uma obra mais próxima do fragmentário, da seleção, da coletânea, do que do fluxo da narração exata" (Miraux, 2005, p. 73, tradução nossa) ${ }^{11}$. Mas esse não é o caso de Manoel de Barros.

Essas últimas observações que aponto, funcionam como uma espécie de chave para repensar a memória na palavra autobiográfica de Manoel de Barros. Explico-me melhor: além dos tradicionais relatos sobre a infância de um menino, mergulhado em um Brasil semiurbano, semirrural, como é frequente nas autobiografias de poetas relativamente contemporâneos a Manoel, essas Memórias inventadas trazem uma corporificação diferente. Seu tema central é o nascimento da poesia; o menino de suas memórias só tem existência na confluência da descoberta da literatura e seus temas poéticos; melhor dito, nas ressignificações para aquilo que sempre foi desprezado pelo cânone. A memória do velho Manoel obedece ao critério da seleção de imagens nas quais os valores afetivos demarcam a poesia que surge das pequenas coisas, dos seres ínfimos. E, como o foco irradiador dessas memórias é a poesia ela mesma, todo o demais será marcado pela diferenciação.

Vou ao livro e sinto no tato e na visão o diferencial nesse volume de memórias. A memória emerge do passado por meio de imagens, mas imagens em movimento, as quais, mergulhadas em um tempo vertical ${ }^{12}$, comportam também um tempo horizontal, porque cada imagem narra um episódio significativo das vivências do menino Manoel que se presentificam no poeta Manoel de Barros.

Esse livro de memórias é composto por treze capítulos e um preâmbulo. Cada capítulo vem precedido de uma ilustração específica. E mais

\footnotetext{
11 “Convierten en la propia condición de la escritura autobiográfica, que se desarrolla una obra más cercana a lo fragmentario, a la selección, al florilegio que al cauce continuo de la narración exacta." ${ }^{12}$ Lembro aqui as referências ao binômio tempo vertical e tempo horizontal proposto por Bachelard, conforme referi em meu artigo “Memória e imaginário” (Souza, 2010).
}

110 estudos de literatura brasileira contemporânea, n.40, jul./dez. 2012, p. 99-112 
ainda: o aspecto formal com que foram planejadas suas memórias, na edição original, apresenta os capítulos em folhas soltas e separadas, porém acondicionadas em uma caixinha. Não há numeração corriqueira das páginas, apenas os números em romanos para indicar uma sequência que sequer segue uma linha de composição histórica. Os episódios são manuseados pelo leitor, que para lê-los necessita retirá-los de dentro da caixinha. Esse ato, quase involuntário, provoca uma intimidade acima do usual entre o poeta e seu leitor, porque o manuseio das partes constitutivas das Memórias inventadas implica o estranhamento característico com que sua obra tem sido recebida tanto pela crítica quanto pelos leitores de poesia.

O que impulsiona a memória de Manoel de Barros são os valores vividos, mas são valores referidos à poesia em possibilidades de formas e de temas, e não à infância no sentido estrito do termo. Bachelard dizia que o passado não é estável e que acorre à memória sempre de maneira diferente. Para ir à memória mais profunda, é preciso reencontrar, para muito além dos fatos, os valores que ficaram. Afirma o filósofo:

Para constituir a poética de uma infância evocada num devaneio, cumpre dar às lembranças sua atmosfera de imagem (...) o passado rememorado não é simplesmente um passado da percepção. Já num devaneio, uma vez que nos lembramos, o passado é designado como valor de imagem (Bachelard, 1988, p. 99).

A memória é uma imagem. A memória de Manoel de Barros busca as imagens da sua poesia. E, como imagens, surgem de capítulo em capítulo, formando, cada uma delas, um pequeno mundo independente. Não à toa, o livro obedece a essa estrutura de blocos autônomos. Cada parte tem sua imagem nuclear e seus "ensinamentos". Estão assim dispostos: "Escova", “Obrar", “Desobjeto", "Parrrede!", “Ver", “O lavador de pedra”, "Fraseador", "Achadouros", "Sobre sucatas", “Cabeludinho", "O apanhador de desperdícios", "Brincadeiras", "A rã", "Caso de amor" e "Latas", perfazendo treze imagens, treze memórias. E, como já mencionei anteriormente, treze é a idade em que nasceu o poeta.

\section{Referências}

BARROS, Manoel de (2003). Memórias inventadas: a infância. São Paulo: Planeta.

(2010). Poesia completa. São Paulo: Leya.

BACHELARD, Gaston (1988). A poética do devaneio. São Paulo: Martins Fontes. CHEVALIER, Jean ; GHEERBRANT, Alain (1997). Dicionário de símbolos. Rio de Janeiro: José Olympio. 
FERREIRA, Agripina (2008). Dicionário de imagens, símbolos, mitos, termos e conceitos bachelardianos. Londrina: EDUEL.

LURKER, Manfred (2003). Dicionário de simbologia. São Paulo: Martins Fontes. MIRAUX, Jean-Philippe (2005). La autobiografía: las escrituras del yo. Buenos Aires: Nueva Visión.

SOUZA, Raquel R. (2002). Boitempo: A poesia autobiográfica de Drummond. Rio Grande: Editora da FURG.

(2010). "Memória e imaginário". In: BERND, Zilá (org.). Dicionário de mobilidades culturais: percursos americanos. Porto Alegre: Literalis.

RICOEUR, Paul (2007). A memória, a história, o esquecimento. Campinas: Editora da Unicamp.

TODOROV, Tzvetan (2000). Los abusos de la memória. Barcelona: Paidós.

Recebido em dezembro de 2011.

Aprovado em março de 2012.

\section{resumolabstract}

\section{Chaves de memórias em Memórias inventadas, de Manoel de Barros}

\section{Raquel R. Souza}

Elegendo o livro Memórias inventadas: a infância, do poeta goiano Manoel de Barros, o artigo pretende se deter na memória e observar os mecanismos por meio dos quais ela atua. A partir do pressuposto básico de que a memória é imaginação, busca-se o apoio teórico da fenomenologia de Gaston Bachelard, relevantemente em um de seus últimos textos no qual se dedica ao exame do devaneio e do devaneio sobre a infância. Ao mesmo tempo, ressaltar-se-á a face referencial da metapoesia como foco irradiador dessas memórias.

Palavras-chave: vestígios memoriais, memória e imaginário, devaneio e memória, memória da poesia, Manoel de Barros.

\section{Keys memories in Memórias inventadas, by Manoel de Barros}

Raquel R. Souza

Electing the book Memórias inventadas: a infância, by Brazilian poet Manoel de Barros, from the state of Goiás, the article intends to observe memory and assess the mechanisms through which it operates. From the basic assumption that memory is imagination, we search the theoretical support of the Phenomenology studies of Gaston Bachelard, relevantly in one of his last texts, which is dedicated to the examination of daydreaming and daydreaming about childhood. At the same time, we highlight the face of referential metapoetry as a focus of radiaton of those memories.

Keywords: memory traces, memory and imaginary, daydreaming and memory, memory of poetry, Manoel de Barros. 